\title{
Buddhaghosa, James, and Thompson on Conscious Flow
}

Forthcoming at Journal of the American Philosophical Association

(please cite published version)

Mark Fortney, The University of Toronto at Scarborough

mark.fortney@mail.utoronto.ca

\begin{abstract}
:
This paper is about whether consciousness flows. Evan Thompson (2014) has recently claimed that the study of binocular rivalry shows that there are some moments where consciousness does not flow, contra William James (1890). Moreover, he's claimed that Abhidharma philosophers reject James's claim that consciousness flows. I argue that binocular rivalry poses no special challenge to James. Second, I argue that because Thompson did not take up the question of how James and Abhidharma philosophers analyse or define flow, he under-described their disagreement in a way that obscures an important conceptual contribution that Abhidharma philosophers make to the study of flow. They reject James's claim that there are only two conceivable ways for consciousness to fail to flow, and suggest that there is a third way for consciousness to fail to flow - a way that James's imagination did not reveal to be possible.
\end{abstract}




\section{Introduction 1}

This paper is about how William James characterizes conscious flow and how his account can help us move forward on recent philosophical debates in scientifically informed philosophy of mind and cross-cultural philosophy of mind. Evan Thompson (2014) has recently claimed that the study of binocular rivalry shows us that there are at least some moments in our lives where consciousness does not actually flow, despite the appearances. Moreover, he's claimed that Abhidharma philosophers reject James's claim that consciousness flows (2014 p. 34-40). ${ }^{2}$

I use my reading of James on conscious flow to reject Thompson's first claim. I also argue that because Thompson did not take up the question of how James and Abhidharma philosophers analyse or define flow, he under-described their reasons for disagreement, thereby obscuring an important conceptual contribution that Abhidharma philosophy makes to the study of flow. According to James, what it usually is for consciousness to flow is for the phenomenology of any two immediately sequential moments of consciousness to overlap to at least some small degree. Sometimes, James also thinks that flow can obtain across gaps of unconsciousness through conscious states on either side of the gap feeling like they belong to the same self. This is an understanding of conscious flow which is compatible with all the experiences that occur during binocular rivalry and compatible with all the neuroscientific facts revealed by research into binocular rivalry.

\footnotetext{
${ }^{1}$ Thanks to two anonymous referees from The Journal of the American Philosophical Association for their very helpful comments on a previous version of this paper.

2 Dunne 2016 has raised the worry, in a review of Thompson that "the Abhidharma" is a broad enough term that it may obscure important differences between various texts and philosophers in that tradition. As we'll see later, my own arguments in this paper rely on a few phenomenological observations that come from one particular text rather than the Abhidharma in general: Buddhaghosa's Visuddhimagga.
} 
Secondly, Thompson under-describes the reasons for disagreement between James and Abhidharma philosophers. To simplify the discussion, in this paper I will focus on the disagreement as it occurs between James and Buddhaghosa. What we can find in Buddhaghosa's work is not simply the rejection of the claim that consciousness flows, but even more interestingly, a rejection of a claim James makes along the way to formulating his thesis about flow - his claim that there are only two conceivable ways for consciousness to fail to flow. The view in Buddhaghosa's work is that there is a third conceivable way for consciousness to fail to flow: through feeling as though it passes out of existence during every moment of consciousness.

So Buddhaghosa's work does support the contention that consciousness doesn't flow. But missing out on the precise sense in which he disagrees with James obscures the radical nature of the contribution that he makes to the debate about conscious flow. To someone with James's theoretical presuppositions, Buddhaghosa's contribution expands logical space rather than simply makes the case for a position within logical space. Giving a right account of their disagreement requires going deeper than Thompson's discussion of this issue, and engaging more with the question of what "flow" in the stream of consciousness really means.

Empirically informed and cross-cultural conversations are both deeply important parts of the philosophy of mind. But these conversations require constant, careful checks into whether we have correctly interpreted all the participants involved. While this paper makes some critical points, this is simply a means to achieving a goal I share with Thompson: ensuring that these conversations flourish. 


\section{James on Conscious Flow}

In "The Stream of Thought" in Principles of Psychology, James begins with arguing that psychology's foundational first data point is that "thought goes on", and then defend defends several more specific theses about what that thought, or consciousness, is like (James 1890 p. 224). One of his first goals is to argue that consciousness is "sensibly continuous" (James 1890 p. 226). By "continuous", James says that he means "that which is without breach, crack, or division" (James 1890 p. 237). What it is for consciousness to be sensibly continuous is for consciousness to feel as though it is without breach, crack, or division.

He uses the "stream of consciousness" metaphor to capture all these ideas. This is what that metaphor looks like: “[consciousness], then, does not appear to itself chopped up in bits. Such words as 'chain' or 'train' do not describe it fitly as it presents itself in the first instance. It is nothing jointed; if flows. A 'river' or a 'stream' are the metaphors by which it is most naturally described" (James 1890 p. 239.) As we can see, this is where James introduces the language of "flow" rather than "sensibly continuity". They mean the same thing for him, but "flow" has simply become a more popular term to express these ideas in recent years.

James's metaphor has been very widely taken up in philosophy and psychology. Many of us seem to agree with James that there is just something right about the idea that our conscious lives do not appear "chopped up in bits", and that our moments of conscious experience to seem to smoothly flow into each other, from one moment to the next. But James would have been surprised at how quickly some of us agree with him. He doesn't think the stream metaphor just obviously applies; he thinks that the claim that the metaphor applies is 
a substantive philosophical conclusion. This is a fact that is missed by readers like Aron Gurwitsch, who say that for James the interconnectedness of conscious states is something so obvious for James that it "need not be established" (Gurwitsch 1943 p. 449).

For James, there are two ways that consciousness can seem to have a breach or a gap that might worry us - gaps in time, and gaps in content. First, there are time gaps of unconsciousness in our lives. But he says that after a state of unconsciousness, what makes the moments before and after the state feel like they belong to the same stream of consciousness is that they feel like they belong to the same self (James 1890 p. 239). Secondly, this is how he describes the worry about gaps in content: "Does not a loud explosion rend the consciousness upon which it abruptly breaks, in twain? Does not every sudden shock, appearance of a new object, or change in a sensation, create a real interruption, sensibly felt as such, which cuts the conscious stream across at the moment at which it appears? Do not such interruptions smite us every hour of our lives, and have we the right, in their presence, still to call our consciousness a continuous stream?" (James 1890 pp. 239-40)

James goes on to defuse the second worry through arguing that closer introspective observation will reveal that no change in the stream of consciousness is truly, totally abrupt. In his view, every two sequential moments of consciousness are somewhat phenomenologically alike, with the feelings in the first moment leaving at least some experiential traces in the feelings that are present in the second moment. This is how James thinks this style of reply applies to his objection about thunder: “... [into] the awareness of the thunder itself the awareness of the previous silence creeps and continues; for what we hear when the thunder crashes is not thunder pure, buts thunder-breaking-upon-silence- 
and-contrasting-with-it" (James 1890 p. 240). There would be a true breach in consciousness if the feeling silence was totally eradicated at the moment of thunder, but because traces of silence remain, there is no true breach.

James thinks this sort of moment-to-moment colouring, overlapping, or similarity is ubiquitous in consciousness. Here is one example of how he describes the phenomenon as it shows up during reading: "If we read 'no more' we expect presently to come upon a 'than'; if we read 'however' at the outset of a sentence it is a 'yet,' a 'still,' or a 'nevertheless,' that we expect... And this foreboding of the coming grammatical scheme combined with each successive uttered word is so practically accurate that a reader incapable of understanding four ideas of the book he is reading aloud, can nevertheless read it with the most delicately modulated expression of intelligence" (James 1890 p. 254).

So James rejects skepticism about the stream metaphor for consciousness through emphasizing his view about what it is for thought to be "sensibly continuous". It is for any two moments in thought to overlap at least slightly in their phenomenology - for the feeling of silence to remain, at least somewhat, in the moment in which the feeling of thunder that follows begins, or for the feeling of "no more" to remain, at least somewhat, when the feeling of the word "than" arrives.

Moreover, James believes that in examining these two types of apparent discontinuity his defense of the stream metaphor has been exhaustive. As he writes before embarking on the defense of the metaphor, these two kinds of breaches in the stream of consciousness are "... [the] only breaches that can well be conceived to occur within the limits of a single mind" (James 1890 p. 237, emphasis mine). As I'll go on to argue in the next section of the paper, James's defense is sufficient to deal with the challenges raised by the phenomenology and 
neuroscience of binocular rivalry, but reading Buddhaghosa's work shows us that there may be a third way for consciousness to fail to flow, a way that James did not consider.

\section{Binocular Rivalry and Flow}

In Waking, Dreaming, Being, after Thompson reviews some literature on binocular rivalry, he raises the following provocative question: "But is the flow of conscious perception really discrete, like the frames of a movie or a series of snapshots? Maybe this way of thinking about perception comes from relying too much on the unusual situation of binocular rivalry" (Thompson 2014 p. 34). In so doing, he is saying that binocular rivalry is a phenomenon which poses at least some counterexamples to the view that moments of consciousness always flow into one another - perhaps because of the phenomenology of binocular rivalry, perhaps because of what the neuroscientific study of binocular rivalry reveals about what goes on our brains during binocular rivalry. I'll argue that neither of these conclusions is the case. As long as we keep in mind James's view of what is actually required for one moment of consciousness to flow into another, we can see that neither the phenomenology nor neuroscience of binocular rivalry poses a challenge to the idea that there is a stream of consciousness.

In binocular rivalry experiments, participants simultaneously view two images. One image is exposed only to the left eye, and one image is exposed only to the right eye. In visual consciousness, participants don't see both images at once. Instead, their experience alternates from an experience of one image to an experience the other image (Thompson 2014 p. 22). With the basic methodology in view, we can consider this question: "In binocular rivalry experiments, from the subject's perspective, does consciousness seem to fail to flow?" 
What might motivate a "yes" answer to this question is the fact that from moment to moment in these experiments, what is presented in the stream of consciousness can be dramatically different. A checkerboard may seem to suddenly change into a face, or a selection of maple leaves may seem to suddenly change into a butterfly, to mention two of Thompson's specific examples (Thompson 2014 p. 29, p. 33).

But this line of thought is structurally identical to James's suggestion that thunder breaking upon silence challenges the "stream" metaphor, and it can be answered in a structurally identical way. As long as there is some trace of the previous moment's experience in the present moment, then the sensible continuity of consciousness has been maintained. And if we look at subjects reporting on the phenomenology of binocular rivalry, it seems as though some of these traces persist.

For instance, of his own experience, Thompson writes:

The two images I'm viewing are a photograph of a woman's face and an expanding ring with a checkerboard pattern. A special setup keeps the two images separate by projecting the face to my right eye and the expanding checkerboard ring to my left eye. As I stare at the screen, the checkerboard ring starts to give way and change into the woman's face. The face breaks through in disconnected patches, which merge and take over the whole screen. A few seconds later, the face falls apart and the expanding checkerboard rings return, removing the face completely (Thompson 2014 p. 21). 
Part of what it is to have the experience gradually change from a checkerboard to a face is for some traces of the complete checkerboard experience to remain in the various stages of experience as the checkerboard changes to the face. These traces are what explain the feeling that something is changing before one's eyes. And even if there weren't these gradual changes - even if the face changed completely abruptly into the checkerboard - there would still be a felt difference between seeing a checkerboard that was a moment ago a face and seeing a checkerboard that was a moment ago a checkerboard. Experiential traces of the previous images are what explains this fact.

Not to mention that we can make use of a resource to which James doesn't consider in his analysis of thunder breaking upon silence - elements of the stream of consciousness outside of the dramatic change under consideration. Even if the switch from the checkerboard to the face is abrupt, part of what makes consciousness seem to flow from one moment to the next is that so much more stays constant in consciousness: the subject's auditory experiences of the quiet room that they are in; the subject's experiences of their own body, the subject's experience of their internal monologue, and so on. So at the level of phenomenological description, there is nothing about binocular rivalry that challenges James's thesis that every moment in the stream of consciousness is sensibly continuous with the next. ${ }^{3}$

\footnotetext{
${ }^{3}$ In this section of the paper I have argued that binocular rivalry does not pose a special challenge for James's analysis of flow, because his analysis seems to apply to it as well as his analysis applies to any of the cases he considered explicitly in Principles of Psychology. But are either of James's analyses of flow - in terms of overlapping contents or feelings of belonging to the same self - actually accurate analyses of the phenomenon of flow? Can we find reason to doubt his introspective descriptions of flow? These are interesting questions that are outside the scope of the present investigation.
} 
But perhaps Thompson thinks that something about the neuroscience of what goes on during binocular rivalry challenges the view that consciousness flows. I'll argue that while the neuroscience doesn't teach us anything about conscious flow, it does teach us about another aspect of consciousness - how quickly it can change in terms of what it presents to a subject.

We can see this through looking to one of the studies that Thompson cites as relevant to the issue of conscious flow - Doesburg et al. 2009 (cited at Thompson 2014 p. 32). In the study, participants pressed a button to indicate when their experience shifted from one image to another image (in the context of binocular rivalry). Doesburg et al. used EEG with an aim to understanding what was going on in the brain when the image shifted from one image to another, from the perspective of a participant. Here is what they say relationship between their observations and conscious flow:

We found that the recurrent gamma-oscillatory network identified in this study was modulated at a theta frequency, consistent with previous studies of endogenous oscillatory synchronization timelocked to perceptual switching in binocular rivalry. This supports the hypothesis that theta-modulated gamma-band synchronizations are essentially related to perceptual experience and define discrete 'frames' of consciousness, consistent with results from attentional blink experiments and those investigating coherent perception of visual images. The distribution of dominance durations in our study, consistent with findings from previous studies, suggests that 
perceptual switching did not occur on every theta cycle. This indicates that the theta cycle determines when a new perceptual experience can occur, but that the content of each 'frame' of consciousness does not need to differ from that of its predecessor...

Although discrete moments of perception can only occur at a certain rate, as demonstrated by the attentional blink phenomenon, subjective consciousness is seamless and continuous rather than presenting itself as a sequence of discrete conscious moments. The results presented here suggest a similar arrangement, as perceptual consciousness is updated by a periodic mechanism but is experienced as a continuous and stream of consciousness (Doesburg et al $2009 \mathrm{p}$. 9).

As this passage makes clear, what Doesburg et al. have really supported is the claim is that there is a certain rhythm at which the contents of consciousness can change (here I use "contents of consciousness" just to mean "what consciousness seems to present to a subject"). It's not the case that every passing millisecond or nanosecond presents an opportunity for the contents of consciousness to change; instead the rhythms that these neuroscientists are studying seem to give us a more accurate sense of when the contents of consciousness can change. This is an interesting result. Perhaps folk psychology tells us that consciousness is more sensitive and changeable than this. If so, we should use result like this one to temper our misplaced confidence in the high sensitivity and changeability of the stream of consciousness. 
Doesburg et al. also say that this finding is in tension with the view that consciousness is a continuous and steady stream, and this is where they make a mistake. All that is required for flow is for the phenomenology of sequential moments of consciousness to overlap at least some degree, and this is compatible with whatever the facts are about the rate of change of contents presented to us via the stream of consciousness. What this study actually supports is a conclusion about the rhythm at which the contents of consciousness can change.

At this point, one might raise the worry that nothing at all could falsify James's view about conscious flow. But this worry would be misplaced. James says that immediately sequential moments of consciousness always feel overlap slightly in their phenomenology, and that moments of consciousness that are divided by a span of unconsciousness still feel like they belong to the same self. But if consciousness doesn't always feel one of these two ways, then James's claim that consciousness always feels sensibly continuous would be mistaken. Perhaps there are experiences he did not consider that falsify his universal claim, or perhaps he did not have sufficient training to describe his experiences accurately, or perhaps he misdescribed his experiences because of some sort of theoretical bias. If any of these possibilities are the case, then James would wrong about conscious flow. As we'll see in the next section of the paper, we can use materials from Buddhaghosa's work to build a criticism along these lines.

\section{Abhidharma and Flow}

Here is where Thompson identifies a disagreement between James and some Abhidharma philosophers on conscious flow: 
The Abhidharma philosophers agree that the mental stream is always changing, but they argue that it appears to flow continuously only to the untrained observer. A deeper examination indicates that the stream of consciousness is made up of discontinuous and discrete moments of awareness. Whether the Abhidharma philosophers arrived at this view through inner observation or through logical analysis premised on an atomistic view of the mind, or some combination of both, is a matter of scholarly debate. In any case, they believed that discrete moments of awareness or "mind moments" can be identified, described, and catalogued; moreover, their duration is said to be measurable (Thompson 2014 p. 35).

Consider the inference at work in the passage above: if it turns out that consciousness is actually made of "discontinuous and discrete moments of awareness", then James's stream metaphor is inaccurate. Consciousness seems to flow but in reality, it does not. Whether this inference is correct, and whether it represents an objection to James grounded in the work of Abhidharma philosophers, depends on just how we interpret "discontinuous and discrete moments of awareness".

If what we mean by "discontinuous and discrete moments awareness" is something like "moments which exist very briefly and are metaphysically independent of each other" then the inference does not make sense as an objection to the view that consciousness flows. This is certainly a claim that we can find in the Abhidharma and Buddhist philosophy more broadly: see von Rospatt 1995 for discussion. But claim does not make sense as an objection 
to James because James's claim about flow is a claim about phenomenology, namely the claim that the phenomenology of any two sequential moments of consciousness will always overlap to a certain extent, or the claim that any two moments will feel like they belong to the same self. The claim is not about the metaphysical priority of any particular temporal unit of experience. Even if every moment of experience is brief and metaphysically independent of all the other moments of experience, these moments could fail to feel as though they are brief and independent of each other. It's possible that they could feel a way that coheres entirely with James's description of the stream of consciousness.

So, if Thompson's inference above offers up a good objection to James, we need evidence that there are moments in streams of consciousness that actually feel discontinuous from each other. And if this truly is an objection to be found in Abhidharma philosophy, what we also need is textual evidence that this phenomenological judgment can be found somewhere in in the works of Abhidharma philosophers.

There is evidence in favour of both of these points, but the evidence is less straightforward than Thompson suggests. Looking at this evidence allows us to see that Thompson misdescribes the nature of the disagreement between James and Abhidharma philosophers. The evidence that I draw on comes from Buddhaghosa's Visuddhimagga (The Path of Purification), in particular. In Visuddhimagga we do not find an observation which simply clashes with James's analysis of conscious flow. Specifically, we do not find the claim that that sometimes, two immediately sequential moments of consciousness are so radically different in content that there is a real breach between them, which is James's account of how consciousness flows in most ordinary, day-to-day experience. What we find instead is a rejection of James's second sense of flow, which James proposed to deal with the special case 
of flow that obtains across moments of unconsciousness. And even more interestingly, what we find is the suggestion that there is a third way for consciousness to fail to flow. I'll discuss these points in turn, focusing more on the latter point.

James's second sense of flow refers to a sense of self: he says that when the stream of consciousness stretches across a period of unconsciousness, flow still obtains because the states before and after the gap feel like they belong to the same self. In the Abhidharma and in Buddhist philosophy more broadly we can frequently find a rejection of the claim that the self, as normally construed, exists (see, e.g. Albahari 2006). This is a metaphysical thesis that is not directly in tension with James's second analysis of flow, which is a phenomenological claim.

But this metaphysical thesis also sometimes comes along with a phenomenological claim does genuinely challenge James's second analysis of flow. For instance, in Buddhaghosa's Visuddhimagga, we can find the claim that we can "liberate" ourselves from perceiving anything at all as our self after engaging in the right kind of contemplative practices. He writes that the meditator "delivers, liberates the mind... from the perception of self by means of the contemplation of not self..." Buddhaghosa (2010 p. 282 / VIII.233). And if this is possible for some subjects, then their streams of consciousness will fail to flow in James's second sense: at least sometimes, they will not feel as though multiple moments of consciousness that are separated by a period of unconsciousness belong to the same self.

Before going on to consider the third sense in which consciousness can be discontinuous, we can consider the following question, which challenges the line of thought above. Is my claim that according to Buddhaghosa we can learn experience two subsequent 
moments as failing to belong to the same self actually incompatible with what Buddhaghosa says about a mental state called bhavanga (Buddhaghosa 2010 p. 458 / XIV.114)?

On Jonardon Ganeri's reading, bhavanga have an intentional content "roughly consisting in autobiographic semantic information" (2017 p. 46). On Rupert Gethin's reading, "a being's bhavanga itself represents a kind of summing up of what he or she did in his or her previous life; in crude terms, it represents a kind of balance sheet carried over from the previous life detailing how one did" (2005 p. 167). If these readings are correct, then bhavanga could be, at least sometimes, a part of the causal explanation of why some subjects experience sequential moments of consciousness as belonging to the same self. But my reading of Buddhaghosa is consistent with such a possibility. In my view, Buddhaghosa would say that while bhavanga might be a part of the causal explanation of why some ordinary, untrained subjects experience sequential moments of consciousness as belonging to the same self, part of the purpose of the meditative practices he describes Visuddhimagga is to train subjects to respond differently to bhavanga, and more broadly, to respond differently to everything in the world, in a way that causes them to abandon the perception of self in all things (Buddhaghosa 2010 p. 282 / VIII.233; p. 632 / XX.4; p. 655 / XX.90).

Secondly, and even more interestingly, in Visuddhimagga we can find the claim that the stream of consciousness can feel discontinuous because we can feel each moment of consciousness pass out of and into existence; that consciousness, like all things, appears to us "perpetually renewed" (Buddhaghosa 2010 pp. 657 / XX.104; ${ }^{1}$ See Gethin 2004 p. 216 for more on this particular passage, as well as my references to Buddhaghosa immediately below). This is a kind of felt discontinuity which is compatible with moments in the stream 
of consciousness overlapping in content and with moments in the stream of consciousness feeling like they belong to the same self. It is a third kind of discontinuity that James did not consider in his analysis of how consciousness might fail to flow.

In these passages, Buddhaghosa describes a meditator who has first engaged in all the contemplative practices described earlier in Visuddhimagga going through a (roughly) three step process which enables her to experience all things as impermanent, and moreover, as constantly destroyed and renewed. The first step is reflecting on the impermanence of materiality and as a result becoming able to experience materiality as impermanent. The second step is reflecting on the impermanence of consciousness and as a result becoming able to experience consciousness as impermanent. The third step is reflecting on the apparent constant creation and destruction of impermanent things, and as a result becoming able to experience all impermanent things as constantly being created, destroyed, and renewed.

One of Buddhaghosa's suggested strategies for achieving the experience of materiality as impermanent is to reflect on how the materiality that shows up in various temporal subdivisions of a body's life all seem like impermanent materiality. For instance, Buddhaghosa suggests that the meditator think of a body's life divided into three equal temporal spans, and noticing that nothing of the materiality from the first third of the life persists in the second third of the life, the meditator should attribute impermanence to the materiality from the first third of the life (Buddhaghosa 2010 pp. 645-646 / XX.47-49). He suggests that the meditator continue to carry out this procedure with narrower and narrower time-slices of a body's life (e.g. the first "tender decade", the second "sport decade", 
and so on) (Buddhaghosa 2010 pp. 646 / XX.51). He also recommends that the meditator carry out an analogous procedure with the materiality that occurs in many other temporal spans, like the span of a year or a season, and that as a result she will thereby eventually gain the ability to perceive the impermanence in materiality (Buddhaghosa 2010 pp. 647 / XX.5657). 4

After engaging in this process, Buddhaghosa says that the meditator can turn her conscious thinking upon the very consciousness with which she was thinking about the impermanence of materiality. He says that the meditator should be able to experience this consciousness that was directed at materiality as impermanent, as well (Buddhaghosa 2010 pp. 652 / XX.79). Moreover, he suggests that this process should be able occur recursively, that is, that the meditator should be able to experience her conscious thinking about her conscious thinking about the impermanence of materiality as impermanent, and so on. (Buddhaghosa 2010 pp. 653 / XX.80-81).

After a meditator has engaged in both sets of contemplative exercises that are focused on the developing the capacity to experience the impermanence of material things and of consciousness, Buddhaghosa says that she is in a position to contemplate change in impermanent things, which he asserts is equivalent to contemplating their constant apparent "rise and fall", that is, their constant apparent creation and destruction (Buddhaghosa 2010 pp. 657 / XX.93-95). The meditator is directed to compare all things to the sound of a lute, which doesn't come from any "store" before it arises or go to any "store"

\footnotetext{
${ }^{4}$ It's important to note that Buddhaghosa is not saying that this process is sufficient for gaining the capacity to perceive impermanence in things, but rather that it's a necessary part of the process - fully describing the process would require a more complete exposition of Visuddhimagga.
} 
after it falls (Buddhaghosa 2010 pp. 657 / XX.96). And after this final contemplative exercise, all things "... appear to [the meditator] as perpetually renewed" (Buddhaghosa 2010 pp. 657 / XX.104). ${ }^{5}$

Expanding on this idea with a set of similes, Buddhaghosa writes: “... they are not only perpetually renewed, but they are also short-lived like dew-drops at sunrise, like a bubble on water, like a line drawn on water, like a mustard seed on an awl's point, like a lightning flash" (Buddhaghosa 2010 pp. 657 / XX.104). And if we really can experience consciousness in this way - always being created and destroyed - then Buddhaghosa has identified a real sense in which there can we can notice breaches in the stream of consciousness. ${ }^{6}$ In James's language, the constant apparent destruction and renewal of consciousness could be a way that consciousness does manage to "... appear to itself chopped up in bits" (James $1890 \mathrm{p}$. 239).

We can see some additional evidence for the idea that Buddhaghosa describes a third way in which consciousness might fail to flow in his analysis of the citta-vithi, or cognitive series, and in his description of how we can put our knowledge of the citta-vitthi to use during meditative practice. On Ganeri's reading of Buddhaghosa, the cognitive series is a sequence of cognitive states that occurs as the mind "oscillates" between taking up a task and occupying its resting state (Ganeri 2017 pp. 42-47). What Ganeri calls the resting state of the mind is a state that Buddhaghosa calls bhavanga, which he says, "goes on occurring

\footnotetext{
${ }^{5}$ Not just material things and consciousness - here I interpret the use of "formations" in the sense of "all conditioned things". See Bodhi (2000 p. 46) for this broadest use of the term.

${ }^{6}$ See Davis (2018) for further discussion of some of these passages from Visuddhimagga and related phenomenological testimony from Mahasi Sayadaw. For work on Buddhaghosa's views more broadly, see Heim (2013) and Ganeri (2017).
} 
endlessly, in periods of dreamless sleep, etc., like the current of a river." (Buddhaghosa 2010 p. 458 / XIV.114). When we are interrupted from this resting state, a series of cognitive events, the citta-vithi, eventually culminates in consciousness of some sort, which persists briefly, and then lapses back into bhavanga.

In the case of visual consciousness, the cognitive series begins with a stimulus impinging the eye, which, if strong enough, will "disturb" bhavanga (Buddhaghosa $2010 \mathrm{p}$. 463 / XIV 115). After this initial disturbance, there will be a sequence of cognitive events that Buddhaghosa says perform functions including "adverting", "receiving", "investigating", "determining", "impulsion", and "registration" (Buddhaghosa 2010 p. 463 / XIV 114 - 124; see also Buddhaghosa 2010 p. 24 / I.57). On Ganeri's reading, "registration" corresponds to "having an object consciously in view" (Ganeri 2017 p. 58). More generally, on Ganeri's reading, all the steps of the cognitive series are performed by mental modules that are analogous to systems identified in contemporary cognitive science, e.g. the "early, middle, and late visual subsystems" (Ganeri 2017 p. 200).

Buddhaghosa draws on our knowledge of the cognitive series, as described above, in one of his descriptions of how a meditator can come to experience consciousness as impermanent. To put that idea into conversation with James, Buddhaghosa draws on our knowledge of the cognitive series in order to help explain how we can learn to experience a failure to flow in consciousness. In this part of the text, Buddhaghosa says that a meditator should reflect on how both material things and consciousness are generated, and that as a result of focusing on their generation, she will come to more deeply understand that they both are things that pass out of existence (Buddhaghosa 2010 pp. 639-645 / XX.22-45). In 
his discussion of reflecting on the generation of consciousness in particular (as opposed to the generation of materiality), Buddhaghosa explicitly invokes the cognitive series as it is defined earlier in the text. He says that the mediator should reflect on how each stage of the cognitive series leads to the generation of consciousness, and that as a result the meditator will more deeply understand that consciousness is impermanent (Buddhaghosa 2010 p. 644 / XX.44-45, p. 644 fn. 18).

This is one of the ways in which we can contemplate impermanence. And according to Buddhaghosa, contemplating impermanence in things is a part of what enables us to really experience them as impermanent (Buddhaghosa 2010 pp. 632 / XX.4). So in his view, the meditator's theoretical knowledge about the cognitive series can be put to practical use in a contemplative exercise that will help enable the meditator to learn to experience consciousness as impermanent. Again, this is a way that Buddhaghosa believes that the right meditative practice can lead us to have experiences in which "consciousness appears to itself chopped into bits" (James 1890 p. 239).

This is why Buddhaghosa is best interpreted as challenging the way James understands his thesis about flow rather than merely as saying that James's thesis is false. To miss out on this fact is to underestimate the contribution Buddhaghosa makes to this discussion. He does not simply defend one option in logical space and disagree with James. Instead, he contends that James has misrepresented logical space, and that the correct view about conscious flow occupies a region of logical space that was inconceivable to James. 


\section{Conclusion}

James claimed that consciousness does not feel like it is chopped into bits. Nothing in the contemporary study of binocular rivalry or the neural correlates of experiences that occur during binocular rivalry challenge this thesis. Instead, what that phenomenon reveals is the degree to which the stream of consciousness is sensitive, and thereby able to rapidly change in felt character. By contrast, Buddhaghosa does make a genuine challenge to James's thesis. But understanding his challenge requires understanding that James analysed flow in two ways, and that Buddhaghosa emphasized a third kind of flow of which James was unaware.

Taking James and Buddhaghosa's claims collectively, this paper has presented three ways in which to analyse the phenomenon of conscious flow. James suggested that sequential moments of consciousness feel like they flow because they overlap in contents or belong to the same self. Buddhaghosa suggested that moments of consciousness can feel like they fail to flow because they feel perpetually renewed. But can we find reasons to doubt the accuracy their introspective reports? Or are there other ways that consciousness can flow or fail to flow? These are interesting questions that all deserve further investigation. 


\section{$\underline{\text { References }}$}

Albahari, M. (2016). Analytical Buddhism: The two-tiered illusion of self. New York: Palgrave MacMillan.

Bodhi, B. (trans). (2000). The Connected Discourses of the Buddha. Somerville: Wisdom Publications.

Buddhaghosa, B. (2010). Visuddhimagga: The path of purification. Trans. by Bhikkhu Ñāṇamoli. Kandy: Buddhist Publication Society.

Davis, J. (2018). “Meditation and consciousness: can we experience experience as broken?". In The Routledge Handbook of Consciousness, pp. 436-449 (ed. R. Gennaro). New York: Routledge.

Doesburg, S. M., Green, J. J., McDonald, J. J., \& Ward, L. M. (2009). “Rhythms of consciousness: Binocular rivalry reveals large-scale oscillatory network dynamics mediating visual perception". PloS One, 4(7).

Dunne, J. D. (2016). “Comments on Waking, Dreaming, Being by Evan Thompson". Philosophy East and West, 66(3), 934-942.

Ganeri, J. (2017). Attention, Not Self. Oxford: Oxford University Press.

Gethin, R. (1994). "Bhavanga and Rebirth According to the Ahidhamma", in V. Pagel and T. Skorupski (eds), The Buddhist Forum III: 11-35. Reprinted in Paul Williams (ed) Buddhism: Critical Concepts in Religious Studies. Volume IV: Abhidharma and Madhyamaka (London: Routledge), pp. 159-181.

Gethin, R. (2004). “On the practice of Buddhist Meditation According to the Pali Nikåyas and Exegetical Sources". Buddhismus in Geschichte und Gegenwart 9, pp. 201-221.

Gurwitsch, A. (1943). "William James' theory of the 'transitive parts' of the stream of consciousness". Philosophy and Phenomenological Research, 3(4), 449-477.

Heim, M. (2013). The Forerunner of All Things: Buddhaghosa on Mind, Intention, and Agency. Oxford: Oxford University Press.

James, W. (1890). The Principles of Psychology. New York: Henry Holt \& Company.

Thompson, E. (2014). Waking, Dreaming, Being: Self and consciousness in neuroscience, meditation, and philosophy. New York: Columbia University Press.

von Rospatt, A. (1995). The Buddhist Doctrine of Momentariness. Stuttgart: Steiner. 